\title{
Limits of Enhanced Weathering potentials - Deductions from column experiments
}

\author{
JENS HARTMANN AND THORBEN AMANN
}

Universität Hamburg

Presenting Author: geo@hattes.de

Carbon dioxide removal efforts become increasingly important to keep climate change targets. The distribution of rock products into soils to remove $\mathrm{CO}_{2}$ from the atmosphere by weathering (Enhanced Weathering) was identified as a method with high potential [1]. However, the majority of assessments is based on modelling studies, which have to rely on a number of assumptions for parameterization, as real-world measurements are still scarce.

In order to elucidate the effects of grain size distribution and soil $\mathrm{pCO}_{2}$ levels, column experiments were set up, simulating humid tropical conditions found in some hotspots of weathering:

- Columns filled with olivine-rich dunite material with three different grain size distributions under fixed atmospheric $\mathrm{CO}_{2}$ conditions

- Columns filled with different materials (dunite, basalt, oxisol, and a combination of the latter two) with a fixed grain size comparing the effects of ambient and saturated $\mathrm{CO}_{2}$ conditions

The weathering fluxes under saturated $\mathrm{CO}_{2}$ conditions are about four times higher in all columns except the dunite column, where fluxes were nearly twelve times higher. Grain size distribution is relevant to study further, as highest weathering rates of dunite were observed in columns with coarser grains, which seems counterintuitive at first.

The findings indicate some important issues to be considered in future experiments and a potential rollout as a carbon dioxide removal method: 1) Only in theory do small grainsizes of the spread material yield large $\mathrm{CO}_{2}$ drawdown potentials. The hydrologic conditions, which determine the residence times, i.e., the time available for weathering reactions, are more important than a small grain size. 2) Saturated $\mathrm{CO}_{2}$ column results provide upper limit estimates for weathering rates. 3) As the carbon accounting is still a problem to solve, the observed setup-specific robust relationship between alkalinity and conductivity might provide an easy-to-handle tool in the future to account for carbon uptake from weathering by measuring conductivity in cropland drainage water.

1. Fuss, S., et al., Negative emissions-Part 2: Costs, potentials and side effects. Environmental Research Letters, 2018. 13(6). 